\title{
Commentary: Esophageal cancer-a story for the ages?
}

\author{
Rajeev Dhupar, MD, MBA, a,b and James D. Luketich, MD
}


burgh School of Medicine, and ${ }^{\mathrm{b}}$ Surgical Services Division, VA Pittsburgh Healthcare System, Pittsburgh, Pa. Disclosures: Authors have nothing to disclose with regard to commercial support.

Received for publication Sept 27, 2019; revisions received Sept 27, 2019; accepted for publication Sept 27, 2019; available ahead of print Nov 6, 2019.

Address for reprints: Rajeev Dhupar, MD, MBA, Department of Cardiothoracic Surgery, Division of Thoracic and Foregut Surgery, Shadyside Medical Building, Suite 715, 5200 Centre Ave, Pittsburgh, PA 15232 (E-mail: dhuparr2@upmc.edu).

J Thorac Cardiovasc Surg 2020;159:329

0022-5223/\$0.00

Published by Elsevier Inc. on behalf of The American Association for Thoracic Surgery https://doi.org/10.1016/j.jtcvs.2019.09.126
}

The last 3 decades have seen progress in the treatment of esophageal cancer, with a reduction in mortality rates for esophagectomy at high-volume specialty centers. We have seen advances in our understanding of the potential advantages of neoadjuvant and adjuvant therapies and progress in our ability to perform minimally invasive esophagectomy. ${ }^{1}$ There is promise that we will witness success with immunotherapies to further improve the outlook for treating this high-mortality cancer. However, while we make progress after the diagnosis is made, appropriate screening and diagnosing guidelines for endoscopy in patients with symptoms that are worrisome for esophageal adenocarcinoma have lagged.

In the current issue of the Journal, Nobel and colleagues ${ }^{2}$ call attention to these guidelines that may limit the timely diagnosis of esophageal cancer. In this study of a large national database, the authors effectively argue that current recommendations for endoscopy specifically discourage it for people who are at significant risk for cancer. For some time, the prevailing wisdom for thoracic surgeons has been that younger patients present with more advanced disease yet do better when they have intervention for locally limited disease, and this manuscript strengthens these ideas. ${ }^{3}$ The authors suggest that aggressiveness of disease can be determined with tumor grade; however, understanding the metastatic potential of cancers and their interactions with the immune system is far more complex than the information that is currently captured in large databases. The question of "aggressiveness" will be better answered by smaller studies of tumor epitope expression and tumor environment.

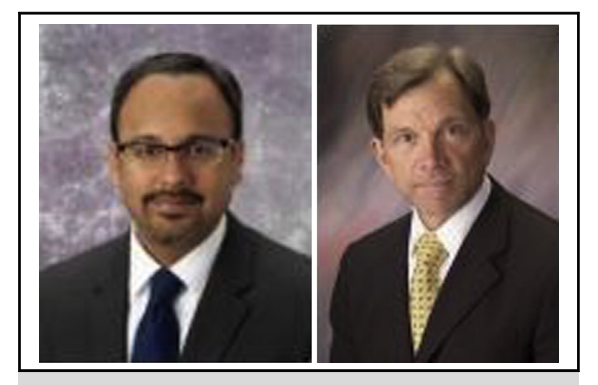

Rajeev Dhupar, MD, MBA, and James D. Luketich MD
Central Message
Given rising rates of esophageal adenocarci-
noma and pressure for more efficient health
care delivery, it is timely that we consider
how our patients are diagnosed.

See Article page 317.
Given rising rates of esophageal adenocarcinoma and pressure for more efficient health care delivery, it is timely that we consider how our patients are diagnosed. Guidelines from major societies are relied on by primary care physicians and gastroenterologists and might be an important justification for triggering referrals for endoscopy in younger patients. If we are to better serve our patients with esophageal cancer who would benefit from aggressive diagnostic measures, we should encourage changes to these guidelines. More studies about younger patients with esophageal cancer will be important, and multidisciplinary efforts toward education in the community and at influential societies will be the next steps. As we learn more about age and incidence of esophageal adenocarcinoma, hopefully we will be able to better serve our patients.

\section{References}

1. Luketich JD. Outcomes after minimally invasive esophagectomy: review of over 1000 patients. Ann Surg. 2012;256:95-103.

2. Nobel TB, Curry M, Gennarelli R, Jones DR, Molena D. Higher clinical suspicion is needed for prompt diagnosis of esophageal adenocarcinoma in young patients. $J$ Thorac Cardiovasc Surg. 2020;159:317-26.e5.

3. Braiteh F, Correa AM, Hofstetter WL, Rice DC, Vaporciyan AA, Walsh GL, et al. Association of age and survival in patients with gastroesophageal cancer undergoing surgery with or without preoperative therapy. Cancer. 2009;115:4450-8. 